\title{
Comparative Study between Imprinted Polymer Technology and Economic Adsorption Methodologies for the Removal of Arsenic Species from Water
}

\author{
Wan Nurul Khairiah¹, Montserrat López-Mesas² and Nurlin Abu Samah¹ \\ ${ }^{1}$ Faculty of Industrial Sciences and Technology, Universiti Malaysia Pahang, 26300, Pahang, Malaysia. \\ ${ }^{2}$ GTS Research Group, Department of Chemistry, Faculty of Science, Universitat Autònoma de Barcelona, 08193 Bellaterra, Spain.
}

\begin{abstract}
Among the various arsenic sources in the environment, water may pose the greatest threat to human health. Arsenic and its compounds are known to have adverse health effects on humans, including skin cancer, bladder cancer, kidney cancer, and lung cancer, as well as vascular diseases of the legs and feet. There are a few separation methods that have been studied to remove arsenic species from water. Methods to remove arsenic species such as adsorption and ion exchange, coagulation and flocculation and membrane filtration have been developed to remove arsenic species from water. However, certain separation methods require a sophisticated equipment and are too expensive. From the different possible methods, this review is based in adsorption studies using imprinted polymer technology and economic sorbents as a media to remove arsenic from water. The details of adsorption processes for imprinted polymer technology have been discussed briefly and the comparative properties for arsenic species removal using different types of sorbents has been addressed significantly for being a user-friendly, highly extended and inexpensive methodology. However, a few drawbacks for each sorbent have been determined and the details was included in this review.
\end{abstract}

ARTICLE HISTORY

Received: $7^{\text {th }}$ Oct 2021

Revised: $11^{\text {th }}$ Nov 2021

Accepted: 1 st Dec 2021

KEYWORDS

Arsenic removal

Review

Adsorption

\section{INTRODUCTION}

More than a decade, arsenic (As) poisoning has become a worldwide problem of high priority [1]. It is considered one of the major concerns in the world when water quality is considered, due to its high risk of health hazards for its contamination in the groundwater sources.

As is found in different valence states, $-3,0,+3$ [arsenite, As(III)] and +5 [arsenate, As(V)], as well as it exists in forms of both inorganic and organic compounds[1]. The natural sources of arsenic in drinking water are weathering of arsenic-containing rocks, biological achievements, and volcanic eruptions [2]. As(III) species include $\mathrm{As}(\mathrm{OH})_{3}, \mathrm{AsO}_{3}{ }^{-}$, $\mathrm{AsO}_{3}{ }^{2-}$ and $\mathrm{AsO}_{3}{ }^{3-}$. As(V) species are $\mathrm{AsO}_{4}{ }^{3-}, \mathrm{AsO}_{4}{ }^{2-}, \mathrm{AsO}_{4}{ }^{-}$and $\mathrm{AsO}_{4}$ [1][3]. As (III) forms complexes preferentially with oxides and nitrogen. The most common arsenic complexes in water are the As(III) complex arsenite, $\left(\mathrm{AsO}_{3}\right)^{-3}$, and the oxidized $\mathrm{As}(\mathrm{V})$ complex arsenate, $\mathrm{H}_{3} \mathrm{AsO}_{4}[4]$. On the other hand, $\mathrm{As}(\mathrm{V})$ forms complexes with sulfides to produce more stable compounds [5]-[7]. There are also organic arsenic species such as arseno-sugars, dimethyl arsenic acid (DMAA) and monomethyl arsenic acid (MMAA)[1], [4], [5].

The major route for entering toxic elements into living organisms is via the food chain, from water to fresh or processed foods, which is considered very serious for the biology and health of man and animals, being a problem of global concern [7], [8]. Focusing in Malaysia, several studies have reported a high level of arsenic concentration in the Langat River, which provides drinking water almost to a one-third population in the Selangor State. Highest total arsenic concentrations were determined at $27.50 \mu \mathrm{g} / \mathrm{L}$ in 2001 and $11 \pm 8 \mu \mathrm{g} / \mathrm{L}$ in the range of $1.79-21.48 \mu \mathrm{g} / \mathrm{L}$ in 2021 at Langat River because of both, natural and anthropogenic sources [9]. Both data shows a remain high total concentration of arsenic allowed in water resources. According to Ong et al., none of the local vegetable samples showed levels greater than 2.00 $\mu \mathrm{g} / \mathrm{g}$ of arsenic in Malaysia [10]. The arsenic contamination in Malaysia did not reach the level of concern to the public at that time. However, the concentration levels of arsenic at 19\% in well water samples from Sabah in 2010 showed levels exceeding those in the WHO health-based guidelines [9]. This indicates that the arsenic level in Malaysia had increased throughout the years due to human activities. Therefore, more attention should be placed on the levels of arsenic in Malaysian plants. In Malaysia, no comprehensive soil reference values are available to establish levels of toxic arsenic for different land uses [10].

There are several methods for arsenic removal. These methods include coagulation and flocculation, precipitation, adsorption, ion exchange and membrane filtration. There also have alternative methods like ozone oxidation, bioremediation, and electrochemical treatments [11]. Coagulation is the destabilization of colloids by neutralizing the forces that keep them apart. Cationic coagulants provide positive electric charges to reduce the negative charge (zeta potential) of the colloids. Flocculation is the action of polymers to form bridges between the larger mass particles or flocs and bind the particles into large agglomerates or clumps. Bridging happens when segments of the linked chain adsorbed 
on different particles and help particles to aggregate. An anionic flocculant will react against a positively charged suspension, adsorbing on the particles and causing destabilization either by bridging or charge neutralization [1], [11], [12]. Some works have been successful in employing precipitation methods in trying to remove As(III) from drinking water [13]. Membrane filtration separates contaminants from water by passing them through a semi-permeable barrier or membrane [14]. Membrane separation is addressed as a pressure-driven process which are divided into four overlapping categories of increasing selectivity: microfiltration (MF), ultrafiltration (UF), nanofiltration (NF) and hyperfiltration or reverse osmosis $(\mathrm{RO})[1]$.

In addition to chemical techniques for the removal of arsenic species from water systems, the sorption of the contaminants from a solution, of low and high concentrations, is regarded to be the best way of removing them from the solution. It is considered a cost-effective technology, and one of the most promising ways to remove arsenic from the water solution [15], [16]. Adsorption from inorganic resources by low-cost adsorbents is regarded as less costly than membrane separation and more flexible than ion exchange [17].

Many scientists have been using innovative technologies, such as the Fe oxides layer on the sand surface to efficiently remove trace metals [5]. The study results show that the use of iron oxide-coated sand for the removal of metal ions from the water is worthwhile [11]. The solid component of red mud, a bauxite waste product, was employed effectively for arsenic elimination [13].

Other studies uses alumina and iron doped alumnia [18] to effectively remove arsenic Many techniques for developing cheaper metal adsorbents, such as microbial biomass, bio-sorbents, sponge, various by-products, and resins have been investigated [13], [19], [20]. Among the different sorbents, waste plant material is promising, since it reuses and valorise a waste.

Arsenic concentrations in Malaysian rivers and lakes are well below $0.01 \mathrm{mg} / \mathrm{L}$ but some instances can be as high as $1.0 \mathrm{mg} / \mathrm{L}$ [21]. In Malaysia, there are 3 independent technologies includes coagulation and flocculation systems which utilize different types of processes: Sedimentation, Dissolved Air Flotation (DAF) or Lamella Clarifier. Figure 1 shows the major process for conventional water treatment [22].

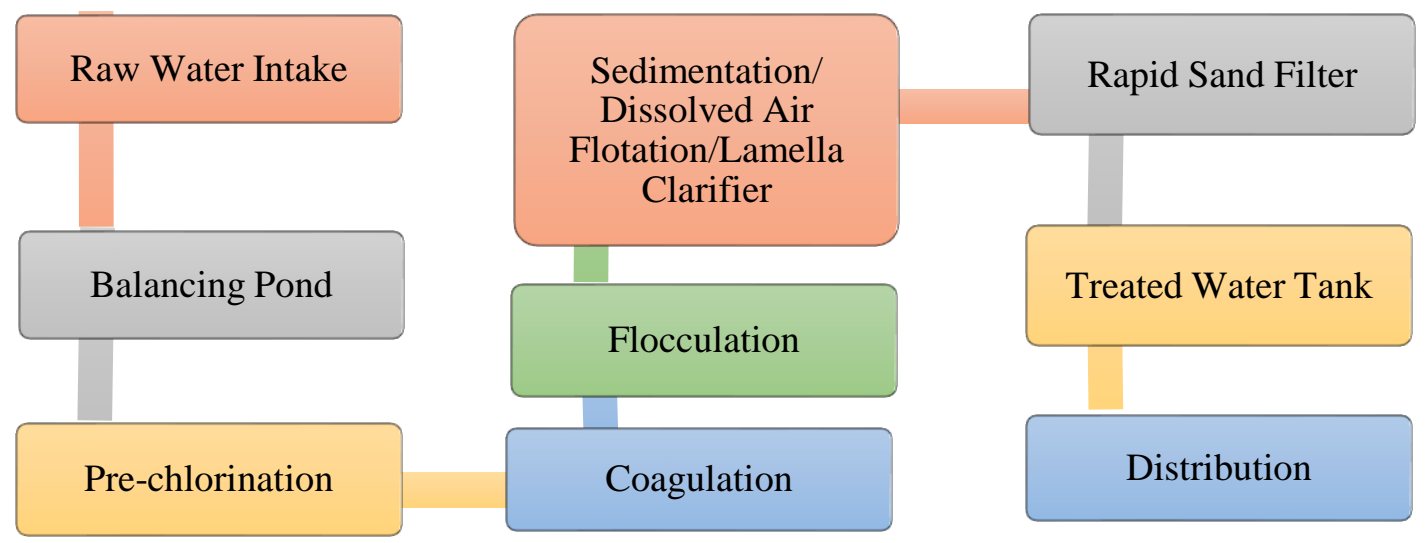

Figure 1. Major process for conventional water treatment.

Current technologies of clean-up are costly. This will place further pressure on rural communities' economies with the adoption of any treatment technology. In sorption technology, there are a few removals methods such as activated carbon and food wastes that has been considered as cheap and affordable alternatives [11].

\section{SORBENTS USED FOR THE REMOVAL OF ARSENIC SPECIES}

\section{ACTIVATED CARBON}

Activated carbons have a wide variety of applications including air and water purification, molecular separation, and chemical recuperation because they have a high surface area, rapid adsorption, and mesoporous structure [23]. They contain functional groups as a result of the activated carbon precursor's oxidation under air and steam at high temperatures or chemistry activation: carboxyl, phenols, esters, and ketones. The presence of these structures on the carbon surface provides them cationic characteristics for exchange [13].

Four different kinds of activated carbons produced from solvent extracted olive pulp and olive stone waste materials were investigated for the elimination of As(III) from aquatic solutions at various concentrations and pH [13]. Chemical activation and physical (water vapor) activation (K2CO3 and $\mathrm{HNO} 3$ ) were used in adsorbents. Results indicated that carbons produce effective arsenic removal by chemical and physical activation of raw olive and olive pulp. Other studies show the Hydrothermal carbonization (HTC) created an iron-coated hydrochar from olive pomace. This adsorbent has an arsenic adsorption capability $(4.1 \mathrm{mg} / \mathrm{g})$ equivalent to that of pyrolysis-produced adsorbents [24]. To improve metal ion adsorption capability, olive stone powder was delignified with sodium chlorite ( $\mathrm{NaClO} 2)[25]$.The removal of arsenic 
follows the order $\mathrm{A}$ (water vapor activation) $>\mathrm{B}(\mathrm{K} 2 \mathrm{CO} 3$ activation of extracted olive pulp) $>\mathrm{C}(\mathrm{K} 2 \mathrm{CO} 3$ activation of olive stones) $>$ D (HNO3 activation). Total elimination of $18.60 \mu \mathrm{mol} / \mathrm{g}$ was determined. [13].

\section{IOWAITE}

Another sorbent used in the removal of arsenic is the Nanocrystalline Iowaite, which is a $\mathrm{Mg} / \mathrm{Fe}$ based double hydroxide (LDH), interspersed with chloride [26]. It has a high rate of arsenic sorption and a considerably better capacity to absorb arsenic than other LDHs typically employed in dearsenic treatment [5]. The major processes for arsenic absorption are the surface adsorption of the compound to iowaite samples via anion exchange with chloride. Specifically, bidentate-binuclear and monodentate-mononuclear As-Fe complexes were found in the arsenate removal tests, whereas bidentate-mononuclear, bidentate-binuclear, and monodentate-mononuclear As-Fe complexes were observed for the arsenite-treated iowaite samples [12]. Nanocrystalline iowaite is a potential low-cost arsenic material for removal from natural water rich in arsenic or polluted high-arsenic waters [26].

\section{IMPRINTED POLYMER TECHNOLOGY}

A molecularly imprinted polymer (MIP) is a polymer that has been treated using the molecular imprinting technology, which leaves holes in the polymer matrix that have a specific affinity for a "template" molecule. The procedure normally includes polymerizing monomers in the presence of a template molecule, which is then removed, leaving corresponding holes behind, which also stabilizes the polymer form. Once prepared, the template is extracted, leaving a particular binding site, able to bind similar compounds to the template [27]. This connection renders the polymer to be insoluble. Thus, modification is commonly required to enhance the ability of imprinted polymers to remove the contaminants from water. Polymerization process is carried out in water bath for preventing swelling. The polymerization is frequently prepared using organic solvents as one kind of synthesized material based on non-covalent interactions, since weak forces between molecules generally achieved (for example hydrogen bonding) are stronger in these solvents [11]. The polymers exhibit remarkable characteristics with ion-printed labelling. Effective affinity, target ion selection, simple and low cost of preparation, reusability, quick handling, and longer life are the features of Ion Imprinted Polymers (IIPs) replaced from MIP [28]. The fundamental concept of imprinted polymer technology using bulk polymerization is shown in Figure 2.
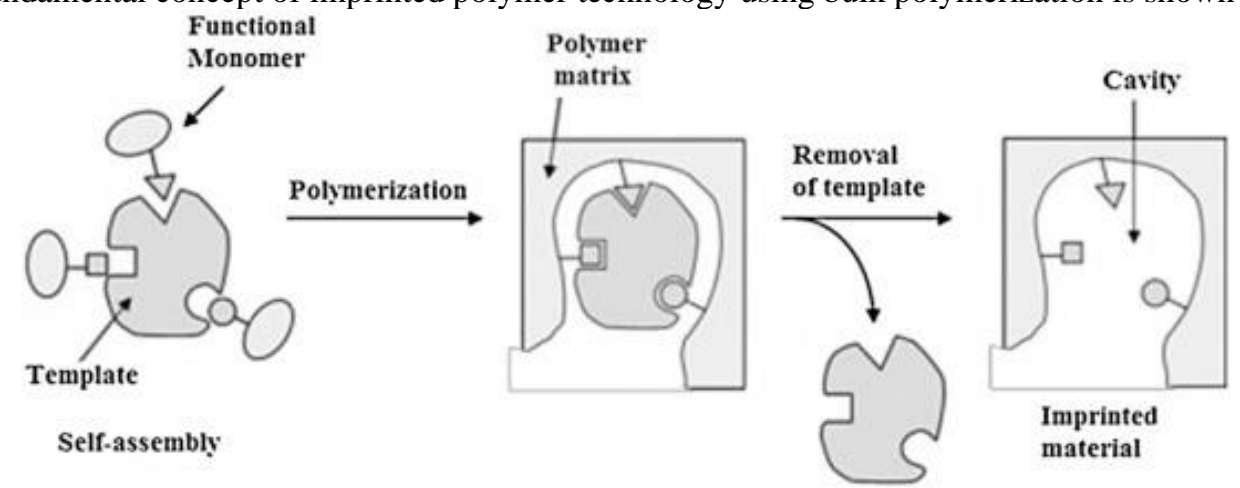

Figure 2. Fundamental concept of imprinted polymer technology. [29]

Molecular Printing Polymerization [28] is an innovative and versatile technique for wastewater treatment primarily utilized for separations, being effective for the separation of enantiomers [27], [28], but also for other applications, such as artificial enzymes and biosensors [11].

During pre-polymerization process, the bonding attachment was based on hydrogen binding through a stable complexing mechanism. The nature type of bonding complexation to sulphur atom and hydrogen atoms were selective [30]. The downfield chemical shift from $6.68 \mathrm{ppm}$ to $7.01 \mathrm{ppm}$ clearly reveals that thiol containing sulphur atom react with arsenic atom because sulphur has the capacity to react with hydrogen atom from the surrounding environment. There was also a downfield chemical shift from $6.13 \mathrm{ppm}$ to $6.32 \mathrm{ppm}$ as a result of the amino groups potentially attaching to the arsenic atom. Furthermore, during adsorption and conversion from arsenite to arsenate, fewer hazardous chemicals are produced during the process. Total loading capacity of up to $0,0679 \mathrm{mmol} / \mathrm{g}$ for initial arsenite was obtained in this saturation investigation conducted by Budinova [13]. The similar finding was found by Abu Samah et al. stated that As(III)-IIP functions as an excellent sorbent with high deletion percentage at $\mathrm{pH} 7$ (90\%) [31].

The desorption of the analysed compound and regeneration of the MIP depend on the selection of the right eluent and regenerating chemical which further depends on the analysed compound mechanism and nature of the adsorbent [32]. Adsorbent regeneration should be a low-cost process aimed at the re-utilization of the adsorbent for as many cycles as possible, to reduce the need for fresh adsorbent and the cost of exhaust adsorbent disposal [33]. For ion-imprinted polymer using magnetic graphene oxide (MGO), regeneration experiments were conducted with five adsorption-desorption cycles. For each cycle, the solution after adsorption was magnetically separated to obtain MGO-As(III)-IIP, using NaOH to desorb As(III) and testing the desorption solution until As(III) was not present; then the adsorbent was washed with deionizing water [34]. The regenerated MGO-As(III)-IIP was reused in the subsequent five-cycle adsorption/desorption experiments. Apart from the highly selective adsorption of target templates, another interesting feature of imprinted 
polymers is re-adsorption [35]. In another study, the newly prepared nano-MIP adsorbent was reported to be easily regenerated by washing with diluted acid and alkaline solutions [29]. The percentage of As(V) desorbed from spent nanoMIP with 0.01 M HNO3, 0.01 M HCl, and 0.01 M NaOH solutions were 98.9, 71.6, and 53.6\%, respectively. This research, which reports the re-adsorption of $\mathrm{As}(\mathrm{V})$ by the regenerated imprinted polymers and compares the re-adsorption using adsorption-desorption-readsorption cycles that were conducted 15 cycles [36].

\section{FOOD WASTES}

Waste valorization as a source of valuable product is linked to resource efficiency and the circular economy. It is generally known that agricultural and agro-industrial activities producea huge quantity of lingo-cellulosic by-products such as fruit peel, straw, stem, stalk, cobs, husk, and bagasse. This review will discuss the use of banana peel and orange peel to eliminate arsenic species from water.

\section{Banana Peel}

According to the findings of the study, banana peel biomass may be employed as an economically viable biosorbent for the removal of As(III) ion from contaminated water. The sorption of As(III) ion was discovered to be $\mathrm{pH}$ and temperature dependent. The greatest percentage removal of As(III) ion was found to be 82.23 percent at $0.843 \mathrm{mg} / \mathrm{g}$ uptake capacity, $\mathrm{pH}$ of 7 , dose of $8 \mathrm{~g}$, contact period of 90 minutes, and reaction temperature of $35^{\circ} \mathrm{C}$. The Freundlich isotherm model $(\mathrm{R} 2=0.993)$ best approximated the equilibrium sorption data. . The absorption rate was initially high, with 70 percent and 90 percent within few minutes but grew slower as the time moved on and equilibrium was reached within 30 min and 75 percent and 95 percent sorption were observed for As(III) and As(V) respectively [15].

\section{Orange Peel}

Orange peel is a cost-effective and locally available bio-sorbent. It has been determined that As(V) is uptaken by orange peel from real groundwater samples through adsorption [37] and from drinking water [38], decreasing the concentration of arsenic below the acceptable levels. Even at very low levels of arsenic and in the presence of concurrent ions, the adsorbent is effective [39].

The mechanism of adsorption of $\mathrm{As}(\mathrm{V})$ on orange peel modified with aluminium hydroxide, may be caused by the production of the orange-bearing modified with aluminium hydroxide on the surface, followed by the replacement, in aqueous media, of the hydroxide anion by the As (V) anion [40].

$$
\left[\mathrm{Al}(\mathrm{OH})_{3}\right]+3 \mathrm{HAsO}_{4}^{-} \rightarrow\left[\mathrm{Al}\left(\mathrm{HAsO}_{4}\right)_{3}\right]+3 \mathrm{OH}^{-} \quad \text { (Equation 1) }
$$

and/or

$$
\left.\left[2 \mathrm{Al}(\mathrm{OH})_{3}\right]+6 \mathrm{HAsO}_{4}^{2-} \rightarrow 2\left[\mathrm{Al}^{(} \mathrm{HAsO}_{4}\right)_{3}\right]+6 \mathrm{OH}^{-} \quad(\text { Equation 2) }
$$

\section{IMPRINTED TECHNOLOGY VERSUS OTHER ADSORBENTS}

Activated carbon removes the whole component in the water body [41]. However, the ionic imprinted polymer can be specific and selective [30]. Activated carbon is unable to be regenerated more than 5 cycles, meanwhile the ionimprinted polymers can be regenerated up to 10 cycles [34], [36]. The As (III) removal percent after each cycle was 60\% and imprinted polymer technology can remove $80 \%$ for each cycle [36], [42]. Whereas, food wastes as an adsorbent, it is possible to remove the arsenic species from water but the food waste commonly made of biodegradable materials. Hence, it will easily degrade and unable to be regenerated more than one cycle.

Production rate of sludge in wastewater treatment plant for activated carbon produces more sludge compared to imprinted polymer technology which can be generated and recycle to sustain the removal process leaching [43]. The activated carbon samples chemically originated from sludge, have shown more appropriate superficial characteristics when submitted to acid leaching. If there was a high water-content in the waste then it must be first dried and then dumped [42]. These pits are easily prone to flooding, leaching of soil and even groundwater [44]. Meanwhile, all of these excellent characteristics make imprinted polymer technology good alternative adsorbents for wastewater treatment [29]. The easy preparation, resistance to hard conditions ( $\mathrm{pH}$, temperature, storage stability), easy to use with real complex examples (directly wastewater) make imprinted polymer technology more suitable for different samples [45].

\section{CONCLUSION}

Overall, the common materials used to remove arsenic species such as food wastes and activated carbon cannot assure the effectiveness of certain adsorbents. Technically, by using food waste and activated carbon as an adsorbent, the arsenic species only being transferred to other places. In adsorption processes using a different kind of sorbent, only imprinted polymer technology does apply regeneration of clean-up cycle up to 10 cycles to remove arsenic species from water. In addition, the imprinted polymer technology was able to recover the arsenic from a water contaminant cocktail and re-used the arsenic species for different purposes. Imprinted technology is a promising technology that can replace the functionality of activated carbon as a powerful sorbent. The application of activated carbon as a powerful sorbent has been well proof and the only problem that might arise was the arsenic species could be removed from the water but unable 
to recover the arsenic via elution processes. Various valorization studies have been conducted on a sustainable biowaste residue in order to recover its matter and energy. Green extraction procedures are used to recover pectin, bioactives/nutraceuticals, and essential oils from waste. The desire to reduce one's environmental imprint, as well as concerns about the depletion of fossil fuels, drove the development of biomass as a sustainable renewable resource for biorefineries.

\section{ACKNOWLEDGEMENT}

The authors would like to thank UMP for funding this work under an internal grant RDU1903106.

\section{REFERENCES}

[1] S. Anjum, D. Gautam, B. Gupta, and S. Ikram, “Arsenic Removal from Water: An Overview of Recent Technologies,” IUP J. Chem., no. 3, pp. 7-52, 2009.

[2] L. Verma and J. Singh, "Synthesis of novel biochar from waste plant litter biomass for the removal of Arsenic (III and V) from aqueous solution: A mechanism characterization, kinetics and thermodynamics," Journal of Environmental Management, vol. 248. 2019, doi: 10.1016/j.jenvman.2019.07.006.

[3] P. Pal et al., "Contamination of groundwater by arsenic: a review of occurrence, causes, impacts, remedies and membranebased purification,” J. Integr. Environ. Sci., vol. 6, no. 4, pp. 295-316, 2009, doi: 10.1080/19438150903185077.

[4] S. N. Ronkart, V. Laurent, P. Carbonnelle, N. Mabon, A. Copin, and J. P. Barthélemy, "Speciation of five arsenic species (arsenite, arsenate, MMAAV, DMAAV and AsBet) in different kind of water by HPLC-ICP-MS," Chemosphere, vol. 66, no. 4, pp. 738-745, Jan. 2007, doi: 10.1016/J.CHEMOSPHERE.2006.07.056.

[5] S. B. Adeloju, S. Khan, and A. F. Patti, "Arsenic contamination of groundwater and its implications for drinking water quality and human health in under- developed countries and remote communities-a review," Appl. Sci., vol. 11, no. 4, pp. 1-25, 2021, doi: 10.3390/app11041926.

[6] D. Mohan and C. U. Pittman, "Arsenic removal from water/wastewater using adsorbents-A critical review," J. Hazard. Mater., vol. 142, no. 1-2, pp. 1-53, 2007, doi: 10.1016/j.jhazmat.2007.01.006.

[7] M. K. Upadhyay, A. Shukla, P. Yadav, and S. Srivastava, "A review of arsenic in crops, vegetables, animals and food products," Food Chem., vol. 276, no. October 2018, pp. 608-618, 2019, doi: 10.1016/j.foodchem.2018.10.069.

[8] A. Kassem, A. Sarheel, and N. Al-Somel, "Determination of trace elements in soil and plants in the Orontes basin of Syria by using instrumental neutron activation analysis," 2004.

[9] M. F. Ahmed, M. Bin Mokhtar, and L. Alam, "Carcinogenic and non-carcinogenic health risk of arsenic ingestion via drinking water in Langat River Basin, Malaysia,” Environ. Geochem. Health, vol. 43, no. 2, pp. 897-914, 2021, doi: 10.1007/s10653020-00571-w.

[10] G. H. Ong, C. K. Yap, M. Maziah, H. Suhaimi, and S. G. Tan, "An investigation of arsenic contamination in Peninsular Malaysia based on Centella asiatica and soil samples,” Environ. Monit. Assess., vol. 185, no. 4, pp. 3243-3254, 2013, doi: 10.1007/s10661-012-2787-6.

[11] T. S. Y. Choong, T. G. Chuah, Y. Robiah, F. L. Gregory Koay, and I. Azni, "Arsenic toxicity, health hazards and removal techniques from water: an overview," Desalination, vol. 217, no. 1-3, pp. 139-166, Nov. 2007, doi: 10.1016/J.DESAL.2007.01.015.

[12] M. Stubbe, U. Broschewitz, G. Kramm, W. Schmidt, and A. Radtke, “Analyse der Konisationen im Zeitraum von 2005-2009 in Rostock," Geburtshilfe Frauenheilkd., vol. 71, no. 3, pp. 187-193, 2011, doi: 10.1055/s-0030-1270755.

[13] T. Budinova, N. Petrov, M. Razvigorova, J. Parra, and P. Galiatsatou, "Removal of arsenic(III) from aqueous solution by activated carbons prepared from solvent extracted olive pulp and olive stones," Ind. Eng. Chem. Res., vol. 45, no. 6, pp. 18961901, 2006, doi: 10.1021/ie051217a.

[14] U. S. Epa, "Arsenic treatment technologies for solid, waste, and water.," USEPA Rep. EPA-542-R-02-004, 2002.

[15] S. Q. Memon, M. I. Bhanger, and J.-U.-R. Memon, "Evaluation of Banana Peel for Treatment," 1st Tech. Meet. Muslim Water Res. Coop., vol. 2008, no. December, pp. 104-109, 2008.

[16] Z. Wang, P. Liao, X. He, P. Wan, B. Hua, and B. Deng, "Enhanced arsenic removal from water by mass re-equilibrium: kinetics and performance evaluation in a binary-adsorbent system," Water Res., vol. 190, p. 116676, 2021, doi: 10.1016/j.watres.2020.116676.

[17] M. S. Jagirani et al., "Preparation of novel arsenic-imprinted polymer for the selective extraction and enhanced adsorption of toxic As3+ ions from the aqueous environment," Polymer Bulletin, vol. 77, no. 10. pp. 5261-5279, 2020, doi: 10.1007/s00289-019-03008-2.

[18] N. Inchaurrondo et al., "Synthesis and adsorption behavior of mesoporous alumina and Fe-doped alumina for the removal of dominant arsenic species in contaminated waters," J. Environ. Chem. Eng., vol. 7, no. 1, 2019, doi: 10.1016/j.jece.2019.102901.

[19] G. A. Kloster, M. Valiente, N. E. Marcovich, and M. A. Mosiewicki, "Adsorption of arsenic onto films based on chitosan and chitosan/nano-iron oxide," Int. J. Biol. Macromol., vol. 165, pp. 1286-1295, 2020, doi: 10.1016/j.ijbiomac.2020.09.244.

[20] D. Morillo, G. Pérez, and M. Valiente, "Efficient arsenic(V) and arsenic(III) removal from acidic solutions with Novel Forager Sponge-loaded superparamagnetic iron oxide nanoparticles," J. Colloid Interface Sci., vol. 453, pp. 132-141, 2015, doi: 10.1016/j.jcis.2015.04.048.

[21] N. Abdul Wahab, "Overview of The Water Services Industry in Malaysia," no. February, 2011, [Online]. Available: http://www.mlit.go.jp/common/000135515.pdf.

[22] S. Perai, "Sungai Dua Water Treatment Plant," pp. 1-13, 2014.

[23] C. Dong, H. Shi, Y. Han, Y. Yang, R. Wang, and J. Men, "Molecularly imprinted polymers by the surface imprinting technique," Eur. Polym. J., vol. 145, no. December 2020, p. 110231, 2021, doi: 10.1016/j.eurpolymj.2020.110231.

[24] L. Capobianco, F. Di Caprio, P. Altimari, M. L. Astolfi, and F. Pagnanelli, "Production of an iron-coated adsorbent for arsenic removal by hydrothermal carbonization of olive pomace: Effect of the feedwater pH," J. Environ. Manage., vol. 273, no. July, 
p. 111164, 2020, doi: 10.1016/j.jenvman.2020.111164.

[25] Y. Gao, M. del C. Aliques Tomas, J. Garemark, X. Sheng, L. Berglund, and Y. Li, "Olive Stone Delignification Toward Efficient Adsorption of Metal Ions," Front. Mater., vol. 8, no. February, pp. 1-7, 2021, doi: 10.3389/fmats.2021.605931.

[26] Q. Guo, Y. Cao, Z. Yin, Z. Yu, Q. Zhao, and Z. Shu, "Enhanced Removal of Arsenic from Water by Synthetic Nanocrystalline Iowaite," Sci. Rep., vol. 7, no. 1, pp. 1-10, 2017, doi: 10.1038/s41598-017-17903-z.

[27] R. Perera, S. Ashraf, and A. Mueller, "The binding of metal ions to molecularly-imprinted polymers," Water Sci. Technol., vol. 75, no. 7, pp. 1643-1650, 2017, doi: 10.2166/wst.2017.036.

[28] S. Ashraf, A. Cluley, C. Mercado, and A. Mueller, "Imprinted polymers for the removal of heavy metal ions from water," Water Sci. Technol., vol. 64, no. 6, pp. 1325-1332, 2011, doi: 10.2166/wst.2011.423.

[29] A. Sarafraz-Yazdi and N. Razavi, "Application of molecularly-imprinted polymers in solid-phase microextraction techniques," TrAC - Trends Anal. Chem., vol. 73, pp. 81-90, 2015, doi: 10.1016/j.trac.2015.05.004.

[30] M. M. Yusoff et al., "Synthesis of ion imprinted polymers for selective recognition and separation of rare earth metals," $J$. Rare Earths, vol. 35, no. 2, pp. 177-186, 2017, doi: 10.1016/S1002-0721(17)60897-4.

[31] N. Abu Samah, N. A. Mat Rosli, A. H. Abdul Manap, Y. F. Abdul Aziz, and M. Mohd Yusoff, "Synthesis \& characterization of ion imprinted polymer for arsenic removal from water: A value addition to the groundwater resources," Chem. Eng. J., vol. 394, no. April, 2020, doi: 10.1016/j.cej.2020.124900.

[32] M. Kapur and M. K. Mondal, "Mass transfer and related phenomena for $\mathrm{Cr}(\mathrm{VI})$ adsorption from aqueous solutions onto Mangifera indica sawdust," Chem. Eng. J., vol. 218, pp. 138-146, 2013, doi: 10.1016/j.cej.2012.12.054.

[33] M. A. Hashim et al., "Arsenic removal by adsorption on activated carbon in a rotating packed bed," J. Water Process Eng., vol. 30, no. November 2016, pp. 0-1, 2019, doi: 10.1016/j.jwpe.2018.03.006.

[34] Z. Chi, Y. Zhu, W. Liu, H. Huang, and H. Li, "Selective removal of As(III) using magnetic graphene oxide ion-imprinted polymer in porous media: Potential effect of external magnetic field," J. Environ. Chem. Eng., vol. 9, no. 4, p. 105671, Aug. 2021, doi: 10.1016/J.JECE.2021.105671.

[35] M. Cejner and R. Dobrowolski, "Ion-imprinted polymers: synthesis, characterization and applications," Ann. Univ. Mariae Curie-Sklodowska, Sect. AA - Chem., vol. 70, no. 2, p. 67, 2016, doi: 10.17951/aa.2015.70.2.67.

[36] J. S. Mankar, M. D. Sharma, and R. J. Krupadam, "Molecularly imprinted nanoparticles (nanoMIPs): an efficient new adsorbent for removal of arsenic from water," J. Mater. Sci., vol. 55, no. 16, pp. 6810-6825, 2020, doi: 10.1007/s10853-02004377-0.

[37] P. D. Pathak, S. A. Mandavgane, and B. D. Kulkarni, "Fruit peel waste as a novel low-cost bio adsorbent," Rev. Chem. Eng., vol. 31, no. 4, pp. 361-381, 2015, doi: 10.1515/revce-2014-0041.

[38] C. C. Chang and R. Li, "Agricultural waste," Water Environ. Res., vol. 91, no. 10, pp. 1150-1167, 2019, doi: 10.1002/wer.1211.

[39] M. I. Khaskheli, S. Q. Memon, A. N. Siyal, and M. Y. Khuhawar, "Use of orange peel waste for Arsenic remediation of drinking water," Waste and Biomass Valorization, vol. 2, no. 4, pp. 423-433, 2011, doi: 10.1007/s12649-011-9081-7.

[40] MoHUA, "Waste To Wealth: A Ready Reckoner for Selection of Technologies for Management of Municipal Solid Waste," Minist. Hous. Urban Aff. Gov. India, p. 22, 2017, [Online]. Available: http://164.100.228.143:8080/sbm/content/writereaddata/Waste to Wealth_2 Oct.pdf.

[41] B. Deng, M. Caviness, and Z. Gu, "Arsenic removal by activated carbon-based materials," ACS Symp. Ser., vol. 915, pp. 284293, 2006, doi: 10.1021/bk-2005-0915.ch020.

[42] M. K. Mondal and R. Garg, "A comprehensive review on removal of arsenic using activated carbon prepared from easily available waste materials," Environ. Sci. Pollut. Res., vol. 24, no. 15, pp. 13295-13306, 2017, doi: 10.1007/s11356-017-88427.

[43] M. A. A. Zaini, M. Zakaria, S. H. Mohd.-Setapar, and M. A. Che-Yunus, "Sludge-adsorbents from palm oil mill effluent for methylene blue removal," J. Environ. Chem. Eng., vol. 1, no. 4, pp. 1091-1098, 2013, doi: 10.1016/j.jece.2013.08.026.

[44] B. B. Law, "The Usage of Domestic Water Filtration Systems in Malaysia," p. 119, 2005.

[45] B. Okutucu, "Wastewater Treatment Using Imprinted Polymeric Adsorbents," Intech, no. tourism, p. 13, 2016, [Online]. Available: https://www.intechopen.com/books/advanced-biometric-technologies/liveness-detection-in-biometrics. 